\title{
Skewing effect of sulprostone on dendritic cell maturation compared with dinoprostone
}

\author{
JENNY BULGARELLI, LAURA FIAMMENGHI, SERENA CASSAN, \\ ANNA MARIA GRANATO, MASSIMILIANO PETRINI, ELENA PANCISI, \\ VALENTINA SOLDATI, FRANCESCO DE ROSA, LAURA RIDOLFI, ANGELA RICCOBON \\ \& MASSIMO GUIDOBONI
}

Unit of Immunotherapy and Somatic Cell Therapy, Istituto Scientifico Romagnolo per lo Studio e la Cura dei Tumori (IRST), Istituto di Ricovero e Cura a Carattere Scientifico (IRCCS), Meldola, Italy

\begin{abstract}
Background. Dendritic cells (DCs) are the most efficient antigen-presenting cells and act at the center of the immune system owing to their ability to control both immune tolerance and immunity. In cancer immunotherapy, DCs play a key role in the regulation of the immune response against tumors and can be generated ex vivo with different cytokine cocktails. Methods. We evaluated the feasibility of dinoprostone $\left(\mathrm{PGE}_{2}\right)$ replacement with the molecular analog sulprostone, in our good manufacturing practice (GMP) protocol for the generation of DC-based cancer vaccine. We characterized the phenotype and the function of DCs matured in the presence of sulprostone as a potential substitute of dinoprostone in the proinflammatory maturation cocktail consisting of tumor necrosis factor alpha (TNF- $\alpha$ ), interleukin-1 beta (IL-1 $\beta$ ) and IL-6. Results. We found that sulprostone invariably reduces the recovery, but does not significantly modify the viability and the purity of DCs. The presence of sulprostone in the maturation cocktail increases the adhesion of single cells and of clusters of DCs to the flask, making them more similar to their immature counterpart in terms of adhesion and spreading proprieties. Moreover, we observed that sulprostone impairs the expression of co-stimulatory molecules and the spontaneous as well as the directed migration capacity of DCs. Discussion. These findings underscore that the synthetic analog sulprostone strongly reduces the functional quality of DCs, thus cannot replace dinoprostone in the maturation cocktail of monocytederived DCs.
\end{abstract}

Key Words: cancer immunotherapy, dendritic cell vaccine, dinoprostone, sulprostone

\section{Introduction}

Cancer vaccines are conceived to rewrite the existing crosstalk between host and tumor, shifting the balance from tumor acceptance toward tumor control to the benefit of the patient. In this scenario, dendritic cells (DCs) are the most efficient antigenpresenting cells and play a crucial role in the regulation of innate and adaptive immune responses $[1,2]$. Tissue-resident immature DCs (iDCs) are characterized by high endocytic activity. In the periphery, iDCs take up non-self antigens and, in the presence of appropriate danger signals, start to mature up-regulating cell surface molecules such as CD80, CD86 and CD40 and enhancing their ability to activate $\mathrm{T}$ cells. At the same time, DCs switch their adhesion and chemokine receptors to migrate toward the lymph nodes, where they present the captured antigens to cytotoxic $\mathrm{T}$ lymphocytes (CTLs) [3].

When talking about anti-cancer immune response, $\mathrm{T}$ cells are widely accepted as the most crucial effector cells of the immune system. In this scenario, several aspects of T-cell immunology might prove relevant for a successful vaccination, the most important of which are CTL priming and activation [4]. T-helper (Th) activation is considered an important aspect for the generation of memory CTL responses and for the secretion of vital cytokines required by other effector cells, including natural killer (NK) cells and macrophages, thereby integrating the innate and the

Correspondence: Jenny Bulgarelli, PhD, Unit of Immunotherapy and Somatic Cell Therapy, Istituto Scientifico Romagnolo per lo Studio e la Cura dei Tumori (IRST), Istituto di Ricovero e Cura a Carattere Scientifico (IRCCS), Meldola, Italy. E-mail: jenny.bulgarelli@irst.emr.it 
adaptive immune systems [5,6]. Likewise, activated Th cells up-regulate the surface expression of CD40L molecules that upon ligation to CD40 expressed by DCs license them for the direct activation of naive $T$ cells [7].

These pivotal properties of DCs render them the principal candidates for antigen delivery in therapeutic vaccination against cancer [8-11]. DCs, generated ex vivo by culturing hematopoietic progenitor cells or monocytes with cytokine combinations, have been extensively tested by us and others as therapeutic vaccines in cancer patients in the last decade [8-11]. The most commonly used protocol for the maturation of DCs calls for a cocktail of proinflammatory cytokines (tumor necrosis factor alpha $[\mathrm{TNF}-\alpha]$, interleukin 6 [IL-6], interleukin 1 beta [IL-1 $\beta]$ and prostaglandin $\left.\mathrm{E} 2\left[\mathrm{PGE}_{2}\right]\right)$ first described by Jonuleit et al. [12].

$\mathrm{PGE}_{2}$, also known as dinoprostone, combined with proinflammatory cytokines, specifically up-regulates the surface expression levels of the chemokine receptor CCR7 on DCs, which recognizes lymph nodederived chemokines, such as CCL19 and CCL21, exerting a key role for the chemotaxis of DCs $[13,14]$.

Following a dinoprostone GMP-grade production discontinuation, we have studied the feasibility of its replacement with GMP-grade sulprostone in the production of anti-tumor DC vaccine. Sulprostone is a dinoprostone analogue classified as a nonsteroidal abortifacient agent, mainly used for pregnancy termination and for the treatment of hemorrhages during delivery $[15,16]$. As the role of sulprostone in the generation of human DCs has never been addressed, in this study we analyzed its effect on the DC maturation process, focusing our attention on recovery, functional phenotype and migratory capacity. We discovered that sulprostone does not adequately induce DC maturation. Indeed, the presence of sulprostone in the cytokine cocktail impairs the upregulation of co-stimulatory molecules and maturation markers and leads to a reduction of DC migration. Concomitantly, sulprostone does not significantly modify the viability and the purity of DCs, while strongly stimulates adhesion decreasing the cells recovery. We conclude that in vitro maturation of DCs with sulprostone compromises the DC quality, thus affecting their use in the GMP protocol for cancer vaccine preparation.

\section{Materials and methods}

\section{Samples collection and DC culture}

After obtaining informed consent in accordance with the Declaration of Helsinki and following a protocol approved by the local Institutional Review Board, peripheral blood mononuclear cells (PBMCs) were collected from three healthy donors and DCs were obtained in vitro from circulating precursors by leukapheresis from seven patients with melanoma. PBMCs were purified using density gradient centrifugation (Lymphosep, Biowest). An aliquot of PBMCs was immediately used for $\mathrm{DC}$ vaccine preparation, and the remaining cells were frozen in bags and cryopreserved in nitrogen vapors until use. A detailed method of mature DC preparation has been described elsewhere [17]. Briefly, DCs were obtained from monocytes by adherence on culture flasks. Then, nonadherent cells were discarded and adherent monocytes were incubated in CellGro DC medium supplemented with IL-4 and granulocyte-macrophage colony stimulating factor (GM-CSF; Cell Genix) for 7 days. On day 7 , the culture medium was discarded and iDCs were cultured for a further 2 days with a cocktail of the following cytokines: TNF $\alpha$, IL- $1 \beta$, IL-6 (Cell Genix) and $1 \mu \mathrm{g} / \mathrm{mL}$ of dinoprostone ( $\mathrm{PGE}_{2}$; Pfizer). In some experiments, dinoprostone was replaced with $1,1.5$ or $2 \mu \mathrm{g} / \mathrm{mL}$ of sulprostone (Bayer). On day 9, mature dendritic cells (m-DCs) were recovered and immediately analyzed or cryopreserved and stored in liquid nitrogen until use. The conditioned media $(\mathrm{CM})$ from $\mathrm{m}-\mathrm{DC}$ culture was also collected by centrifugation at $1600 \mathrm{rpm}$ for $10 \mathrm{~min}$ and stored at $-20^{\circ} \mathrm{C}$ before being assayed. For interferon gamma (INF- $\gamma$ ) Enzyme-linked ImmunoSpot (ELISPOT) assay, untouched $\mathrm{CD}^{+} \mathrm{T}$ cells were isolated from healthy donor PBMCs by means of a Pan $\mathrm{T}$ isolation kit (Miltenyi Biotech).

\section{Quality control on m-DCs}

\section{Viability, purity and recovery}

$\mathrm{m}-\mathrm{DC}$ viability, purity and recovery were analyzed using trypan blue exclusion assay and using optical microscope observation for all of the experimental conditions tested.

\section{Safety tests}

For all of the established cultures, endotoxin ( $\leq 0.5$ endotoxin units $(\mathrm{EU}) / \mathrm{mL}$ ), sterility and mycoplasma tests were performed in accordance with European Pharmacopoeia guidelines.

\section{Flow cytometry}

The phenotypic analysis of m-DCs was performed using flow cytometry. Cells were stained with the following monoclonal antibodies and the relative isotype controls: anti-CD80 phycoerythrin (PE), anti-CD86 fluorescein isothiocyanate (FITC), anti-HLA-DR PE, anti-CCR7 PE (BD Pharmingen) and anti-CD83 FITC (Beckman Coulter). Samples were acquired with FACS Canto flow cytometer (Becton Dickinson) and 
the data were analyzed using Diva software (Becton Dickinson) and using FlowJo Software (Tree Star).

\section{Migration assay}

Migration assays were carried out on m-DCs in a 24well plate containing a $5-\mu \mathrm{m}$ pore size polyethylene terephthalate (PET) insert (Millipore). Briefly, m-DCs were washed thoroughly and $100 \mu \mathrm{L}$ of cell suspension in Roswell Park Memorial Institute (RPMI) media $\left(10^{6}\right.$ cells $\left./ \mathrm{mL}\right)$ was added to inserts. At the same time, $250 \mathrm{ng} / \mathrm{mL}$ CCL19, $250 \mathrm{ng} / \mathrm{mL}$ CCL2 1 and a combination of the two ligands of the CCR7 chemokine receptor at $125 \mathrm{ng} / \mathrm{mL}$ each (PeproTech) were placed in RPMI $(600 \mu \mathrm{L})$ in the bottom compartment. Alternately, RPMI media alone was used in the bottom chamber as a control for spontaneous DC migration. Then cells were allowed to migrate for $3 \mathrm{~h}$ in a $5 \% \mathrm{CO}_{2}$ humidified incubator at $37^{\circ} \mathrm{C}$. A $500-\mu \mathrm{L}$ aliquot of media from the lower chamber was picked up and the migrated cells were counted using flow cytometry for a fixed period of 120 seconds at a constant speed. Values are given as mean counts of migrated cell \pm standard error of the mean (SEM).

\section{INF- $\gamma$ ELISPOT assay}

The co-stimulatory ability of m-DCs to trigger a cytokine secretion response in allogeneic $\mathrm{T}$ cells, in the presence of sub-stimulating doses $(0.005 \mathrm{mg} /$ $\mathrm{mL}$ ) of the anti-CD3 antibody OKT3, was assessed using IFN- $\gamma$ ELISPOT assay as a read-out system, following a modified version of the COSTIM assay [18]. Briefly, reference $\mathrm{T}$ cells $\left(10^{5} /\right.$ well) were co-cultured in quadruplicate with $\mathrm{m}-\mathrm{DCs}$ in IFN- $\gamma$-coated ELISPOT plates at the T:DC ratio of 10:1, in the presence of $0.005 \mathrm{mg} / \mathrm{mL}$ OKT3. DCs alone were used as negative controls. To ensure intra- and inter-assay reproducibility, reference $T$ cells from the same three healthy donors were used for each experiment. After a 24 -h incubation in a $5 \% \mathrm{CO}_{2}$ humidified incubator at $37^{\circ} \mathrm{C}$, plates were developed, according to the manufacturer's instructions, and evaluated using a computer-assisted ELISPOT reader (Eli.Expert, A.EL.VIS, GmbH). The distribution of Spot Forming Cell (SFC) number across the different experimental conditions (sulprostone-DCs vs dinoprostoneDCs) was evaluated according to the Student $t$ test.

\section{Multiplex cytokine immunoassay}

The levels of inflammatory cytokines IL-1 $\beta$, IL-6, IL$8, \mathrm{IL}-10, \mathrm{TNF} \alpha$ and IL-12p70 in conditioned media were determined using the Human 6-plex cytokine chemiluminescent Protein Array (Ciraplex; Aushon Biosystems).

\section{Statistical analysis}

The statistics used for data analysis were based on twotailed Student $t$ test for averages comparison in paired samples. Data are presented as mean and SEM is depicted as error bars. $P$ values were calculated using Student $t$ test $\left({ }^{\star} P<0.05 ;{ }^{\star \star} P<0.01 ;{ }^{\star \star \star} P<0.001\right.$; \# $0.05<P<0.1)$.

\section{Results}

Sulprostone induces adhesion and impairs the recovery of $m-D C s$

To evaluate whether sulprostone could be equivalent to dinoprostone in the process of DC maturation, first, we replaced dinoprostone with sulprostone at different concentrations in the in vitro generation of DCs and checked the viability, the purity and the recovery of the final product. Sulprostone did not significantly modify the viability and the purity of DCs. In particular, the attested cell viability was $87.6 \%$ $( \pm 1.6 \%), 86.9 \%( \pm 3.0 \%)$ and $88.2 \%( \pm 2.2 \%)$ upon maturation with $1,1.5$ and $2 \mu \mathrm{g} / \mathrm{mL}$ sulprostone, respectively, compared with dinoprostone-matured sample $(90.9 \% \pm 1.7 \%)(\mathrm{n}=4, \mathrm{n}=10$ for dinoprostone and sulprostone $1 \mu \mathrm{g} / \mathrm{mL}, \# 0.05<P<0.1$; Figure $1 \mathrm{~A}$ ). The recorded purity was of $75.3 \%( \pm 3.7 \%), 66.4 \%$ $( \pm 5.3 \%)$ and $69.6 \%( \pm 3.9 \%)$ upon maturation with $1,1.5$ and $2 \mu \mathrm{g} / \mathrm{mL}$ sulprostone, respectively, compared with dinoprostone-matured sample $(79.3 \% \pm 4.3 \%)(\mathrm{n}=4, \mathrm{n}=10$ for dinoprostone and sulprostone $1 \mu \mathrm{g} / \mathrm{mL}, \# 0.05<P<0.1$; Figure 1B). Interestingly, we observed that sulprostone invariably reduces the recovery of DCs from the culture in all samples. Specifically, the recovery decreased to $5.9 \%$ $( \pm 1.4 \%), 6.0 \%( \pm 0.7 \%)$ and $6.2 \%( \pm 1.1 \%)$ upon maturation with $1,1.5$ and $2 \mu \mathrm{g} / \mathrm{mL}$ sulprostone, respectively, compared with dinoprostone sample $(6.9 \% \pm 1.3 \%)(\mathrm{n}=4, \mathrm{n}=10$ for dinoprostone and sulprostone $1 \mathrm{ug} / \mathrm{mL} ;{ }^{\star} P<0.05 ;{ }^{\star}{ }^{\star} P<0.01$; Figure 1C). Indeed, we found that sulprostone induced a more adherent phenotype on DCs compared with dinoprostone, leading to a reduction of the recovery and the mobility of m-DCs. We observed that sulprostone reduces the number of DC clusters in suspension, and strongly increases DC adhesion to the plastic flask to $435.8 \%( \pm 124.2 \%), 316.7 \%( \pm 148.1 \%)$ and $308.3 \%( \pm 96.1 \%)$ compared with dinoprostonematured cells $(100 \%)(n=3, n=6$ for dinoprostone and sulprostone $1 \mathrm{ug} / \mathrm{mL} ;{ }^{\star} P<0.05$; Figure $2 \mathrm{~A}$ and B). Consistently, the microscope observation and the handling of the cell culture confirmed these observations. Thus, sulprostone prevents the full maturation of DCs, restraining them more similar to their immature counterpart in terms of adhesion and spreading proprieties. 
A

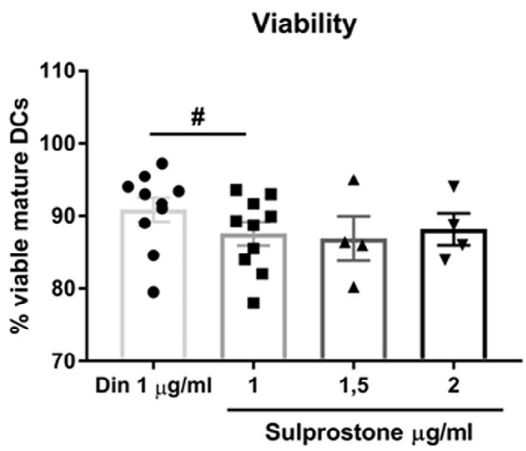

B

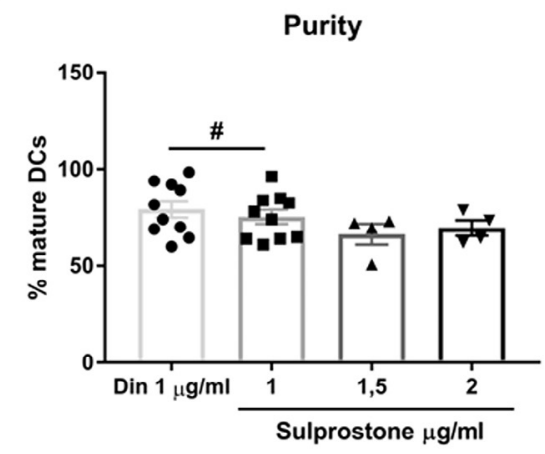

C

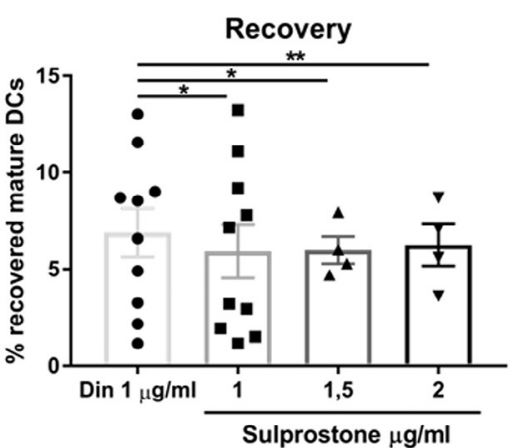

Figure 1. Viability, purity and recovery of dinoprostone and sulprostone-matured DCs. Scatter plots with bar represent the viability (A), the purity (B) and the recovery (C) of m-DCs obtained after a 9-day culture and matured in the presence of dinoprostone or sulprostone at different concentrations for $48 \mathrm{~h}$. Viability was calculated using trypan blue exclusion test as percentage of viable cells on the total cell number; purity was defined as percentage of DCs on the total cell number (lymphocytes and DCs; $\mathrm{n}=4, \mathrm{n}=10$ for dinoprostone and sulprostone $1 \mu \mathrm{g} / \mathrm{mL} ; \# 0.05<P<0.1)$. The recovery of m-DCs was calculated comparing the number of m-DCs with the initial number of cultured PBMCs $\left(\mathrm{n}=4, \mathrm{n}=10\right.$ for dinoprostone and sulprostone $\left.1 \mu \mathrm{g} / \mathrm{mL} ;{ }^{\star} P<0.05 ;{ }^{\star \star} P<0.01\right)$.

\section{Sulprostone reduces the expression of CCR7 and impairs migration of DCs}

Given the observed adhesive behavior of sulprostonematured DCs, we speculated that also migratory and motility properties of these cells might be modified by the molecule. To determine the effects exerted by sulprostone, we performed chemotaxis assays on m-DCs obtained with dinoprostone or sulprostone using $250 \mathrm{ng} / \mathrm{mL}$ CCL19, $250 \mathrm{ng} / \mathrm{mL}$ CCL21, a combination of both at $125 \mathrm{ng} / \mathrm{mL}$ each as chemoattractants or media alone as control (spontaneous migration). Dinoprostone-matured DCs showed a higher migration mediated by chemokine combination $(523 \pm 143.3)$ compared with sulprostone-matured DCs $\left(211 \pm 122.6\right.$; Figure $\left.3 A ; n=3,{ }^{\star} P<0.05\right)$. We also explored the migratory effect exerted by higher doses of sulprostone and we found that sulprostone impairs spontaneous and directed DC migration independently from its concentration (Figure $3 \mathrm{~B} ; \mathrm{n}=3$, $\mathrm{n}=6$ for dinoprostone and sulprostone $1 \mathrm{ug} / \mathrm{mL}$, $\left.{ }^{\star} P<0.05, \# 0.05<P<0.1\right)$. The migratory capacity of DCs has been shown to rely on the surface expression of CCR7 [19]. Thus, we analyzed the expression of this receptor on $\mathrm{m}-\mathrm{DCs}$ and we confirmed that the observed reduced migratory ability of sulprostonematured DCs is in line with the strong down-regulation of CCR7 surface expression. (Figure 3C; $\mathrm{n}=4$, $\left.{ }^{*} P<0.05\right)$ In accord with other studies, these findings indicate that dinoprostone is necessary for CCR7 surface expression on DCs and for their migratory ability [14].

Sulprostone prevents the appropriate maturation of DCs and the surface expression of co-stimulatory markers

We then asked ourselves whether sulprostone could interfere with the co-stimulatory and the proinflammatory profile of m-DCs. Phenotypic analysis showed a down-regulation of co-stimulatory molecules and of maturation markers in sulprostonematured DCs compared with dinoprostone-matured ones. We found a significant down-regulation of the mean fluorescence intensity (MFI) for CD83, CD86 and CD40 markers (Figure $4 ; \mathrm{n}=4, \mathrm{n}=3$ for CD40 MFI expression; $\left.{ }^{\star} P<0.05 ;{ }^{\star \star} P<0.01 ;{ }^{\star \star \star} P<0.001\right)$. Interestingly, sulprostone-matured DCs were CD $14^{+}$, independent from the concentration, suggesting the occurrence of an unsuccessful DC maturation process. However, all populations expressed comparable 
A

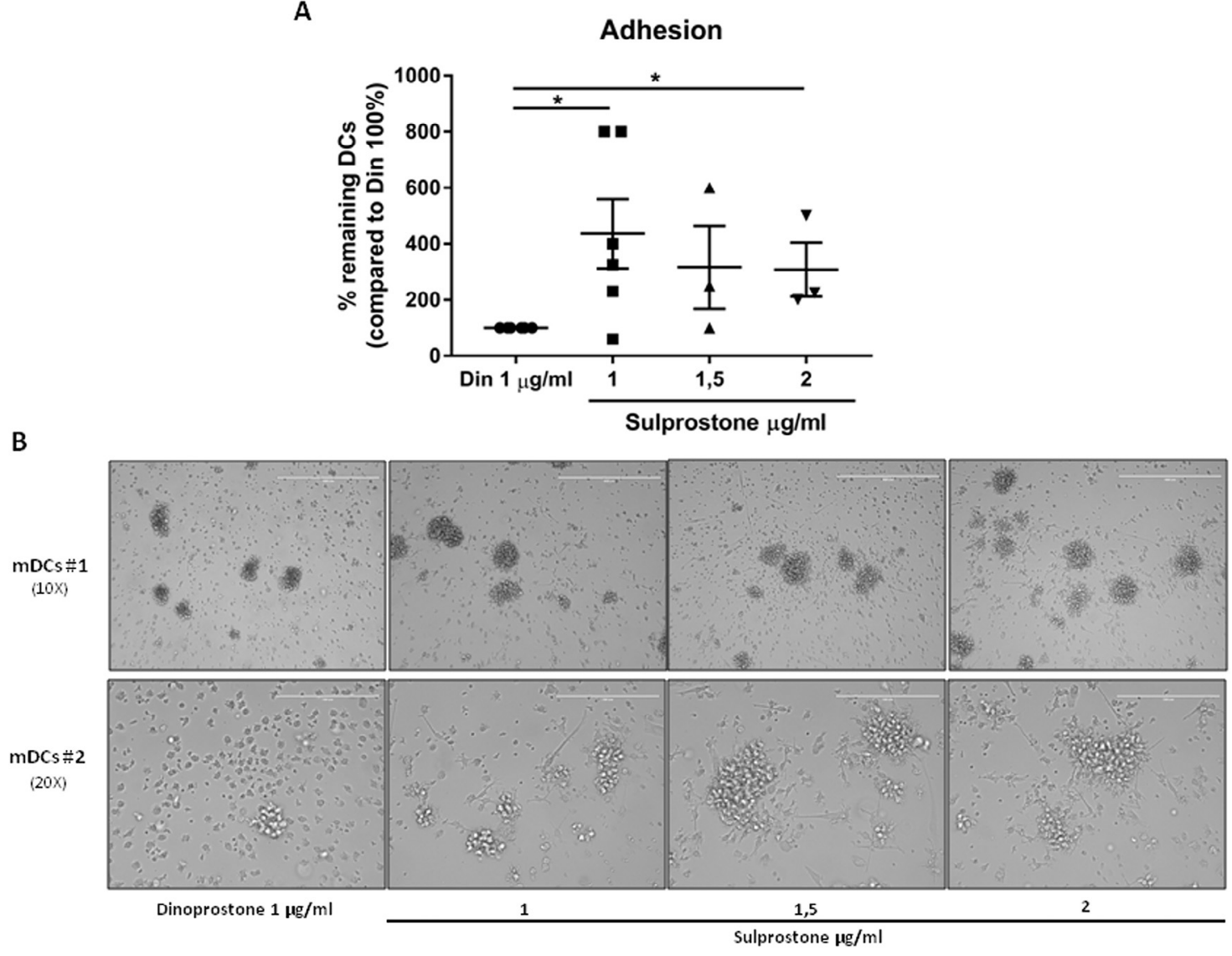

Figure 2. Sulprostone stimulates the adhesion and induces a stretch phenotype on DCs. (A) Scatter plot represents the mean relative adhesion of DCs matured in the presence of different concentrations of sulprostone compared with dinoprostone. m-DCs were recovered and analyzed; thereafter the firmly adherent cells were harvested with subsequent cycles of cooling and washing and counted. (B) Representative phase-contrast micrographs demonstrating an increased number of DCs with stretched, flattened and adherent phenotype after maturation in the presence of sulprostone (first row \#1 original magnification 10x; second row \#2 original magnification 20x).

amounts of HLA-DR, CD80 and CD209 markers (Figure $4 ; \mathrm{n}=4, P=$ not significant [ns]; CD209 MFI data not shown). In addition, we measured the secreted levels of pro-inflammatory cytokines in the conditioned media collected after DC maturation. Compared with media from dinoprostone-matured DCs, media from $1 \mu \mathrm{g} / \mathrm{mL}$ sulprostone-matured DCs contains higher levels of IL-10 $(701.5 \mathrm{pg} / \mathrm{mL}$ and $964.6 \mathrm{pg} / \mathrm{mL}$, respectively; $\mathrm{n}=3, \mathrm{n}=5$ for dinoprostone and $1 \mu \mathrm{g} / \mathrm{mL}$ sulprostone conditions; $\left.{ }^{\star} P<0.05\right)$. The levels of the other inflammatory cytokines did not significantly change among samples and tested conditions (Figure 5A).

Sulprostone-matured DCs are less effective to stimulate $T$ cells

To examine whether differences in co-stimulatory molecules expression phenotype and maturation status between dinoprostone and sulprostone-matured DCs impact on their efficacy to stimulate a T-cell response, we performed an allogeneic potency assay by means of INF- $\gamma$ ELISPOT. Briefly, reference T cells $\left(10^{5} /\right.$ well $)$ were co-cultured in quadruplicate with $\mathrm{m}$-DCs in IFN- $\gamma$-coated ELISPOT plates at the T:DC ratio of 10:1, in the presence of $0.005 \mathrm{mg} / \mathrm{mL} \mathrm{OKT3.}$ We found that, under suboptimal CD3 stimulation condition, sulprostone-matured DCs were less efficient to induce INF- $\gamma$ secretion by $\mathrm{CD}^{+} \mathrm{T}$ cells. The mean relative SFC number decreased to $65.7 \%( \pm 9.6 \%)$, $80.3 \%( \pm 16.4 \%)$ and $90.5 \%( \pm 6.7 \%)$ with $1,1.5$ and $2 \mu \mathrm{g} / \mathrm{mL}$ sulprostone, respectively, compared with dinoprostone-matured cells $(100 \% ; \mathrm{n}=3$, $\# 0.05<P<0.1)$. Interestingly, we observed that $1 \mu \mathrm{g} /$ $\mathrm{mL}$ sulprostone-matured DCs had the lowest capacity to stimulate allogeneic $\mathrm{T}$ cells (Figure 5B).

\section{Discussion}

Several clinical studies in which tumor-antigenloaded DCs are used as cancer therapeutic vaccination indicate that the maturation status of DCs has an important role in initiating and directing anti-tumor immune response [20,21]. 
A

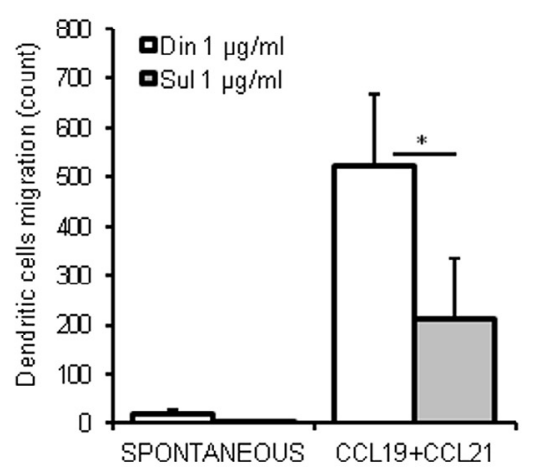

B

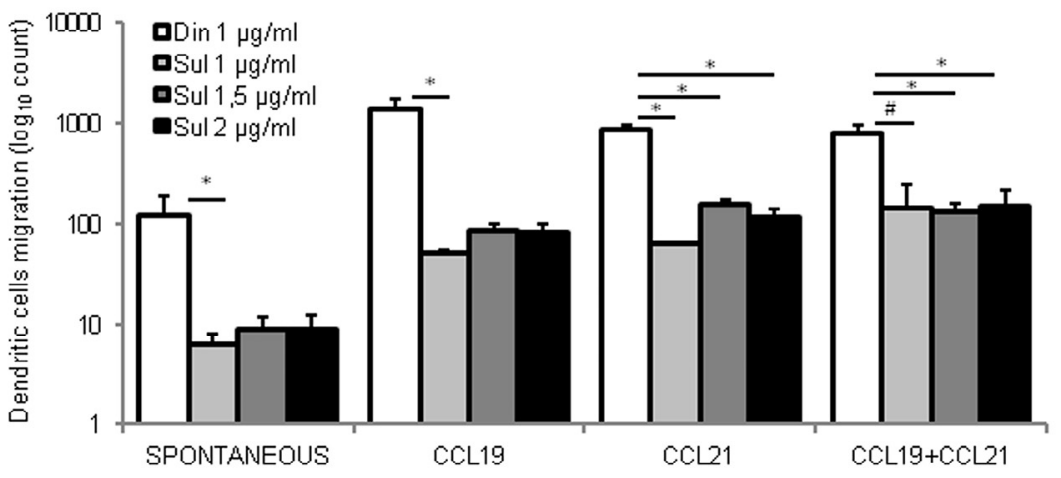

C
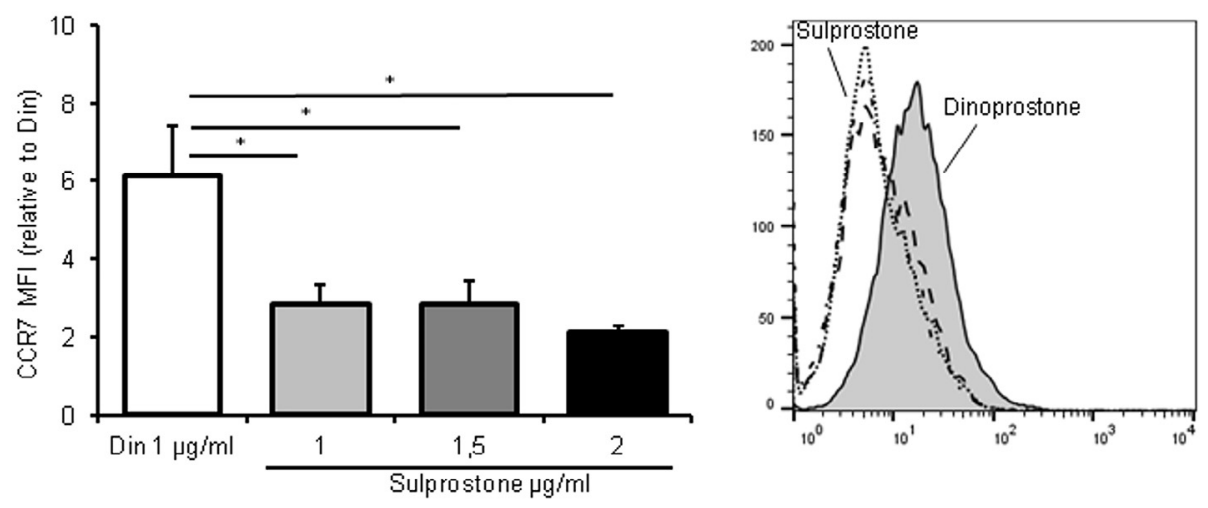

Figure 3. Sulprostone modifies migratory properties and CCR7 expression on m-DCs. Sulprostone reduces migration of DCs. (A and B) m-DCs obtained with $1,1.5$ and $2 \mu \mathrm{g} / \mathrm{mL}$ of sulprostone or $1 \mu \mathrm{g} / \mathrm{mL}$ dinoprostone were loaded in the upper chamber of 5 -mm pore PET inserts. CCL19 $(250 \mathrm{ng} / \mathrm{mL})$, CCL21 $(250 \mathrm{ng} / \mathrm{mL})$, a combination of CCL19 and CCL21 (125 ng/mL each) or RPMI media alone (control for spontaneous DC migration) were added in the bottom chamber as chemoattractants. DCs were allowed to migrate for $3 \mathrm{~h}$ and migrated cells were quantified using flow cytometry for a fixed period of 120 seconds at a constant speed. Values are given as mean counts of migrated cell \pm SEM. Histograms represent mean \pm SEM of three independent experiments (A) and three or six for dinoprostone and sulprostone $1 \mathrm{ug} / \mathrm{mL}$ independent experiments (B) (Student $t$ test; ${ }^{\star} P<0.05$; $\# 0.05<P<0.1$ ). (C) Bar diagram shows cumulative analysis of CCR7 MFI for 4 independent experiments. On the right, the histogram shows mean fluorescence intensity (MFI) of CCR7 in one representative sample calculated subtracting the relative isotype control. Grey histogram represents the dinoprostone $1 \mu \mathrm{g} / \mathrm{mL}$ condition; dotted, dashed and complex line histograms represent sulprostone $1,1.5$ and $2 \mu \mathrm{g} / \mathrm{mL}$ conditions, respectively.

m-DCs display highly efficient antigen processing and presentation machinery and are characterized by down-regulation of antigen-capture activity, increased expression of surface major histocompatibility complex (MHC) class II molecules and co-stimulatory molecules, as well as acquisition of CCR7 which allows migration of the DC to the draining lymph node.

Indeed, it has been convincingly demonstrated that the maturation state of the cells critically influences the efficacy of DC vaccines, mainly related to a terminal differentiation process that transform DCs from poorly immunostimulatory cells specialized in antigen capture into cells specialized in T-cell stimulation $[22,23]$. To date, most clinical trials have been conducted with DCs matured with the Jonuleit maturation cytokine cocktail referred to as the "gold standard" [12]. Indeed, this cocktail was shown to be superior to iDCs in several clinical studies and durable clini- cally responses were reported [10,24-26]. Altenatively, Kalinski and co-workers developed a "megacytokine cocktail" protocol consisting of five reagents: TNF, IL- $1 \beta$, PolyI:C, INF- $\alpha$ and INF- $\gamma$. DCs matured with this cocktail, also called alpha-type 1-polarized DCs $(\alpha \mathrm{DC} 1 \mathrm{~s})$, exhibit superior immunogenicity and retain the ability of CCL21-directed migration, although they are less effective than standard m-DCs [27]. Similar to $\alpha \mathrm{DC} 1 \mathrm{~s}$, other groups have combined single tolllike receptor (TLR) ligands (polyinosinic-polycytidilic acid [PolyI:C], lipopolysaccharide [LPS] or monophosphoryl lipid A [MPLA]) with INF- $\gamma$ to potently induce IL-12 secretion and tumor-specific immune response. Nevertheless, in some studies, DC maturation with these combinations resulted in reduced viability and increased adherence to cell culture plastic [28-30]. Furthermore, the potent early stage activation induced in DCs by stimulation with LPS and 

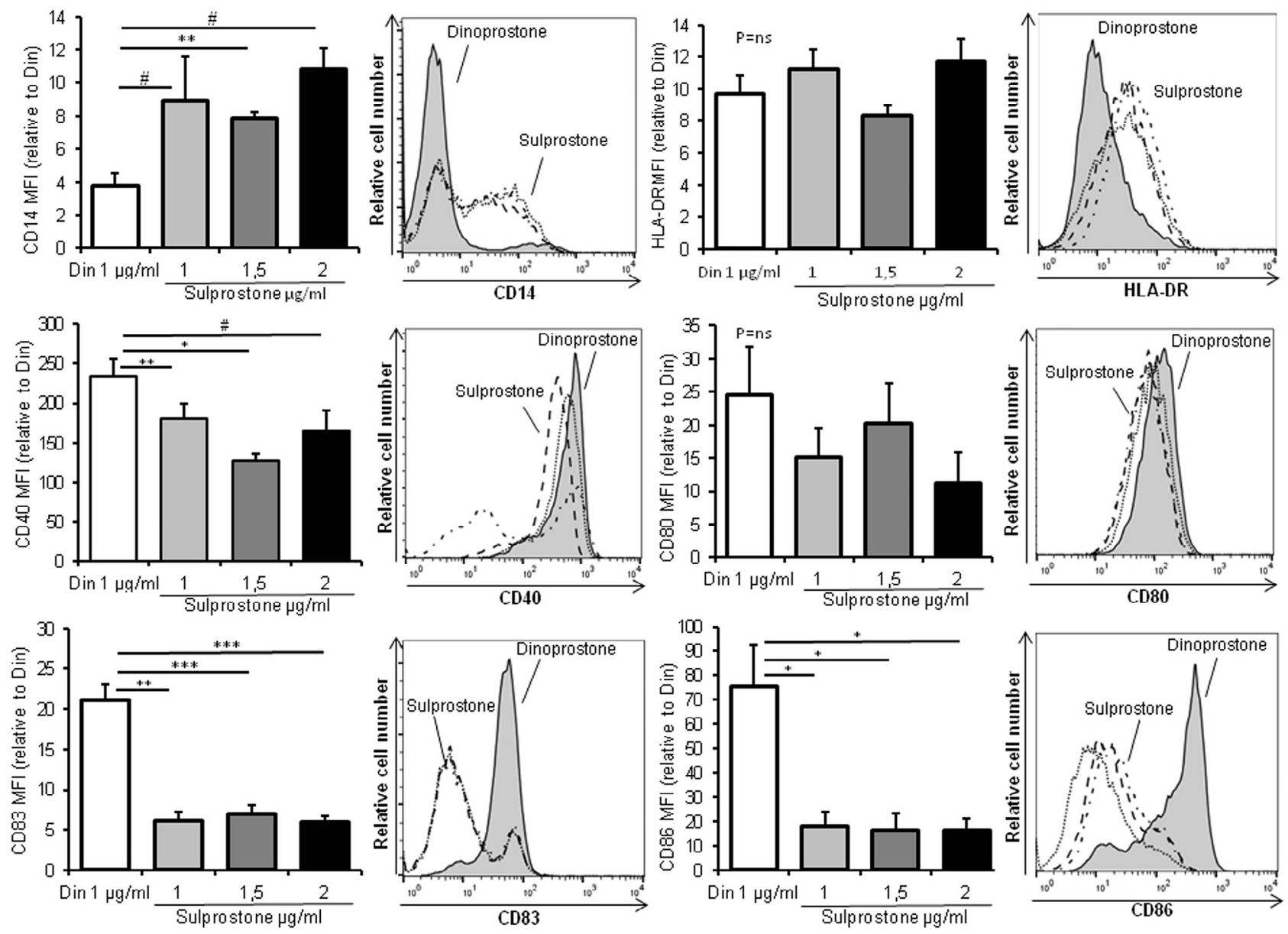

Figure 4. Exposure of DCs to sulprostone alters the surface expression of co-stimulatory molecules. m-DCs were stained with monoclonal antibodies (mAbs) against antigen-presentation and co-stimulatory molecules. Bar diagrams show the MFI of DCs relative to four independent experiments; histograms show the expression in one representative sample for each molecule. Grey histogram represents the dinoprostone $1 \mu \mathrm{g} / \mathrm{mL}$ condition; dotted, dashed and complex line histograms represent sulprostone $1,1.5 \mathrm{and} 2 \mu \mathrm{g} / \mathrm{mL}$ conditions, respectively. DCs matured in the presence of sulprostone, independent from the used concentration, restrain high levels of CD14 surface expression. Sulprostone does not significantly modify HLADR and CD80 surface expression on DCs. Conversely, CD83, CD86 and CD40 are importantly downregulated by sulprostone (Student $t$ test; ${ }^{\star} P<0.05 ;{ }^{\star}{ }^{\star} P<0.01 ;{ }^{\star \star \star} P<0.001 ; \# 0.05<P<0.1$ ).

INF- $\gamma$ is followed by a late stage concomitant activation of regulatory mechanisms, such as the expression of indoleamine 2,3-dioxygenase (IDO) on 48-h matured DCs, which in turn induce regulatory activity in allogenic $\mathrm{T}$ cells [31].

The most impressive difference between standard matured and polarized DCs is the inclusion of prostaglandin E2 (PGE2). This lipid mediator, also called dinoprostone, stimulates a broad spectrum of responses in immune cells and critically regulates DC generation, maturation and migration through four G-protein-coupled receptors (GPCR) subtypes (EP14). Dinoprostone matured-DCs up-regulate the expression of CCR7 and directly migrate toward CCL21 gradient, but also induce a strong T-cell proliferation [32-34]. By contrast, a reduced number of previous data are available regarding the role of sulprostone, a dinoprostone-synthetic anolog, on myeloid cells [35-37].

In this study we aimed to extensively analyze the effects of sulprostone on DCs, investigating whether this molecular analog could replace dinoprostone in the cytokine maturation cocktail to overcome its GMP production discontinuation. To the best of our knowledge, this is the first work in which the effect of sulprostone on DC maturation is investigated. From the GMP point of view, the use of sulprostone is "safe", meaning that DCs matured with this molecule give rise to a sterile product (i.e., endotoxin- and mycoplasma-free). Moreover, in our experience sulprostone does not considerably modify the purity and the viability of DCs, but strongly reduces the recovery of cultured cells. Besides the poor recovery, we observed a reduced number of DC clusters in 

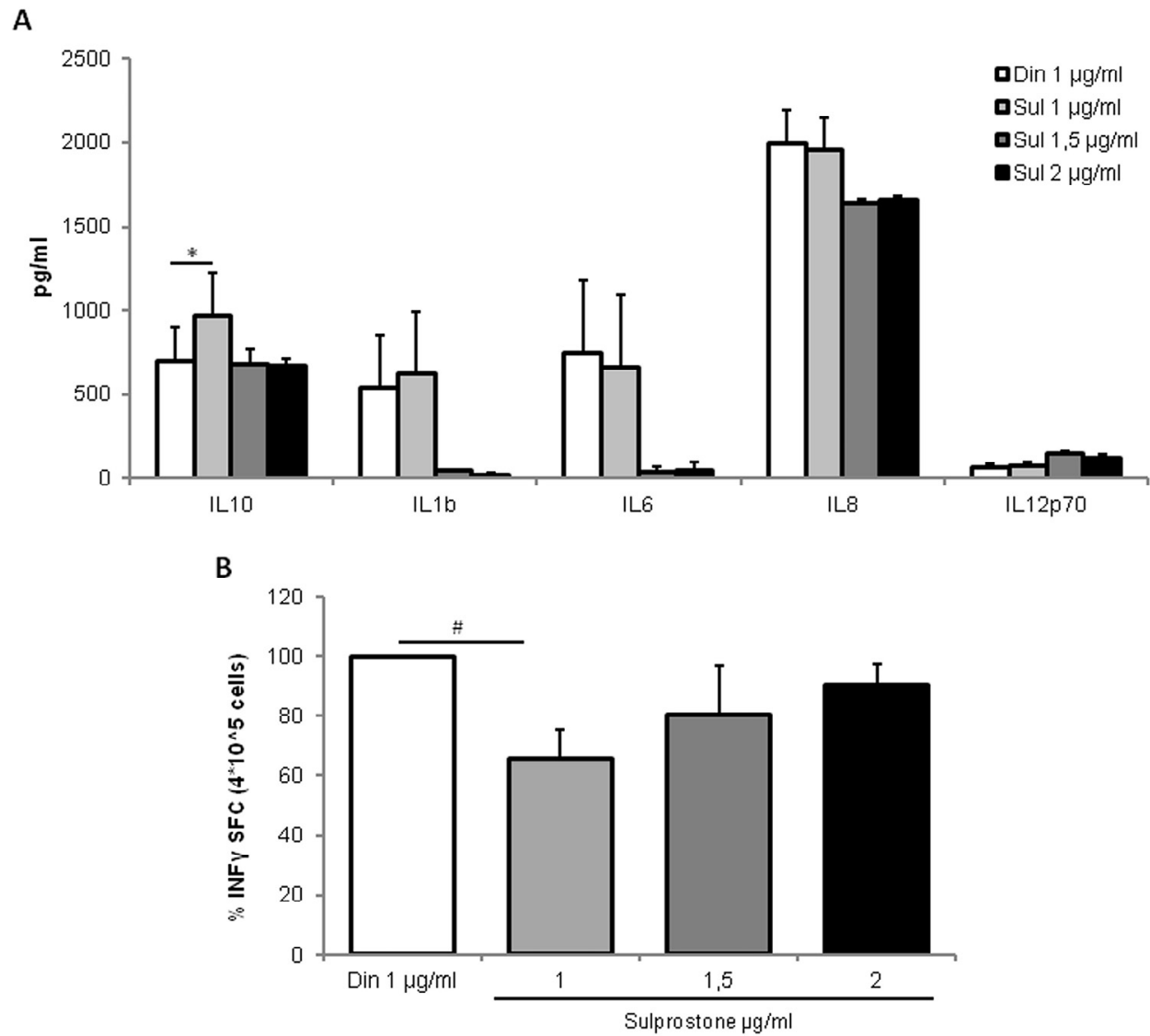

Figure 5. Sulprostone-matured DCs are less able to stimulate T cells. DCs were matured in the presence of dinoprostone or sulprostone at different concentrations for $48 \mathrm{~h}$, at which time the CM was harvested for multiplex enzyme-linked immunosorbent assay (ELISA) determination of IL-1 $\beta$, IL-6, IL-8, IL-10 and IL12p70. (A) Histograms represent the mean protein concentration in $\mathrm{pg} / \mathrm{mL} \pm \mathrm{SEM}$ of independent experiments. We measured a slight increase of IL-10 levels in $1 \mu \mathrm{g} / \mathrm{mL}$ sulprostone condition compared with dinoprostone condition ( $\mathrm{n}=3$, $\mathrm{n}=5$ for dinoprostone and $1 \mu \mathrm{g} / \mathrm{mL}$ sulprostone conditions; Student $t$ test; ${ }^{\star} P<0.05$ ). (B) ELISPOT assay evaluated the number of INF- $\gamma$ SFCs in the presence of a sub-optimal amount of anti-CD3 antibody (CD3 ${ }^{+}$cells alone stimulated with a sub-optimal amount of antiCD3 antibody was considered the control condition). Data demonstrate less robust $\mathrm{CD}^{+}{ }^{+} \mathrm{INF}-\gamma$ responses induced by sulprostonematured DCs compared with dinoprostone-matured DCs. Data are presented as percentage of means \pm SEM from three different healthy donor for three independent experiments and are referred to dinoprostone condition taken as $100 \%$ induction of INF- $\gamma$ SFCs (Student $t$ test; ${ }^{\#} 0.05<P<0.1$ ).

suspension and a high number of adherent DCs with a very low motility. Indeed sulprostone, independent from the used concentration, induces a stretched phenotype on DCs, hampering cells motility. Of note, these features are some of the most extensively studied phenotypic characteristics that distinguish iDCs from the mature counterpart $[24,38]$. These data consistently show that sulprostone prevents the full maturation of DCs, restraining them to an immature phenotype in terms of adhesion and spreading proprieties. Furthermore, in a chemotaxis assay, dinoprostone- and sulprostone-treated DCs performed completely differently. We found that sulprostone impairs spontaneous and directed DC migration toward CCL19 and CCL21 chemokines independently from its concentration and, interestingly, this is in line with the strong down-regulation of CCR7 surface expression that we observed on sulprostone-matured DCs. As explained by others, CCR7 expression is required for the migration of mature DCs into the T-cell areas of the lymph nodes where the antigen presentation takes place $[14,39,40]$. Dinoprostone may thus have key regulatory functions in DC maturation, such as the transition from adhesive to a strong migratory state, mediated by the dissolution of specific integrin- and actin-rich adhesive structures called podosomes; this behavior is not recapitulated by sulprostone.

Besides stimulating DC migration, dinoprostone plays a role in enhancing DCs ability to stimulate $\mathrm{T}$ cells by inducing the up-regulation of co-stimulatory receptors such as OX40L, CD70 and 4-1BBL early during DC maturation, increasing the capacity to induce proliferation of $\mathrm{CD}^{+}$and $\mathrm{CD} 8^{+} \mathrm{T}$ cells $[41,42]$. In line with this view, in our phenotypic analysis, we found an impressive down-regulation of co-stimulatory molecules and of maturation markers (e.g., CD83, 
CD86 and CD40) in sulprostone-matured DCs compared with dinoprostone-matured ones. Conversely, the surface expression of the CD14 marker is maintained, suggesting the occurrence of an unsuccessful DC maturation process. Lastly, we found that sulprostone-matured DCs secrete slightly higher levels of the immunosuppressive cytokine IL-10 and less efficiently induce INF- $\gamma$ secretion by $\mathrm{CD}^{+} \mathrm{T}$ cells compared with dinoprostone-matured cells.

Within the current study we did not investigate the biological mechanisms behind the reported weak activity of sulprostone on DC maturation compared with dinoprostone. The observed reduced activity might be mediated by the interplay of different GPCR subtypes acting on the DC surface or due to a distinct chemical activity exerted by the molecules inside the cell, however, we are aware that all of these aspects need further investigation.

Overall, the data described in this study represent the first exploration of the effects of the dinoprostone-synthetic analog sulprostone on the DC maturation process. Our findings suggest that sulprostone induces only a partial differentiation state on DCs and restrains them in an immature state. Because the inclusion of sulprostone as a substitute for dinoprostone in the cytokine maturation cocktail of DCs not only reduces the recovery of cells, but also impairs the functional quality of DCs, it should not be considered an option in the production of DCbased cancer vaccines.

\section{Acknowledgments}

The authors would like to thank all patients and people involved in the GMP production of DC-based cancer vaccines. This research did not receive any specific grant from funding agencies in the public, commercial or not-for-profit sectors.

Disclosure of interests: The authors declare no conflicts of interest.

\section{References}

[1] Banchereau J, Steinman R. Dendritic cells and the control of immunity. Nature 1998;392:245-52.

[2] Figdor C, de Vries I, Lesterhuis W, Melief C. Dendritic cell immunotherapy: mapping the way. Nat Med 2004;10:475-80.

[3] Palucka K, Banchereau J. Dendritic-cell-based therapeutic cancer vaccines. Immunity 2013;39:38-48.

[4] Kessler J, Melief C. Identification of T-cell epitopes for cancer immunotherapy. Leukemia 2007;21:1859-74.

[5] Jego G, Pascual V, Palucka AK, Banchereau J. Dendritic cells control B cell growth and differentiation. Curr Dir Autoimmun 2005;8:124-39.

[6] Thomas R, Yang X. NK-DC crosstalk in immunity to microbial infection. J Immunol Res 2016;2016:6374379.

[7] Assudani D, Horton R, Mathieu M, McArdle S, Rees R. The role of CD4(+) $\mathrm{T}$ cell help in cancer immunity and the formulation of novel cancer vaccines. Cancer Immunol Immunother 2007;56:70-80.

[8] Ueno H, Schmitt N, Klechevsky E, Pedroza-Gonzalez A, Matsui T, Zurawski G, et al. Harnessing human dendritic cell subsets for medicine. Immunol Rev 2010;234:199-212.

[9] Sabado RL, Bhardwaj N. Directing dendritic cell immunotherapy towards successful cancer treatment. Immunotherapy 2010;2:37-56.

[10] de Rosa F, Ridolfi L, Fiammenghi L, Petrini M, Granato AM, Ancarani V, et al. Dendritic cell vaccination for metastatic melanoma: a 14-year monoinstitutional experience. Melanoma Res 2017;27:351-7.

[11] Tacken PJ, de Vries IJ, Torensma R, Figdor CG. Dendritic-cell immunotherapy: from ex vivo loading to in vivo targeting. Nat Rev Immunol 2007;7:790-802.

[12] Jonuleit H, Kühn U, Müller G, Steinbrink K, Paragnik L, Schmitt E, et al. Pro-inflammatory cytokines and prostaglandins induce maturation of potent immunostimulatory dendritic cells under fetal calf serum-free conditions. Eur J Immunol 1997;27:3135-42.

[13] Luft T, Jefford M, Luetjens P, Toy T, Hochrein H, Masterman KA, et al. Functionally distinct dendritic cell (DC) populations induced by physiologic stimuli: prostaglandin $\mathrm{E}(2)$ regulates the migratory capacity of specific DC subsets. Blood 2002;100:1362-72.

[14] Scandella E, Men Y, Gillessen S, Förster R, Groettrup M. Prostaglandin E2 is a key factor for CCR7 surface expression and migration of monocyte-derived dendritic cells. Blood 2002; 100:1354-61.

[15] Schillinger E, Prior G, Speckenbach A, Wellershoff S. Receptor binding in various tissues of PGE2, PGF2 alpha and sulprostone, a novel PGE2-derivative. Prostaglandins 1979;18:292-302.

[16] Pasterk L, Philipose S, Eller K, Marsche G, Heinemann A, Schuligoi R. The EP3 agonist sulprostone enhances platelet adhesion but not thrombus formation under flow conditions. Pharmacology 2015;96:137-43.

[17] Ridolfi R, Petrini M, Fiammenghi L, Stefanelli M, Ridolfi L, Ballardini M, et al. Improved overall survival in dendritic cell vaccination-induced immunoreactive subgroup of advanced melanoma patients. JTransl Med 2006;4:36.

[18] Shankar G, Bader R, Lodge P. The COSTIM bioassay: a novel potency test for dendritic cells. J Immunol Methods 2004;285:293-9.

[19] Yen JH, Kong W, Ganea D. IFN-beta inhibits dendritic cell migration through STAT-1-mediated transcriptional suppression of CCR7 and matrix metalloproteinase 9. J Immunol 2010;184:3478-86.

[20] Dhodapkar MV, Steinman RM, Krasovsky J, Munz C, Bhardwaj N. Antigen-specific inhibition of effector T cell function in humans after injection of immature dendritic cells. J Exp Med 2001;193:233-8.

[21] Sheng KC, Pietersz GA, Wright MD, Apostolopoulos V. Dendritic cells: activation and maturation-applications for cancer immunotherapy. Curr Med Chem 2005;12:1783-800.

[22] McIlroy D, Gregoire M. Optimizing dendritic cell-based anticancer immunotherapy: maturation state does have clinical impact. Cancer Immunol Immunother 2003;52:583-91.

[23] Nair S, McLaughlin C, Weizer A, Su Z, Boczkowski D, Dannull $\mathrm{J}$, et al. Injection of immature dendritic cells into adjuvant-treated skin obviates the need for ex vivo maturation. J Immunol 2003;171:6275-82.

[24] De Vries IJ, Krooshoop DJ, Scharenborg NM, Lesterhuis WJ, Diepstra JH, Van Muijen GN, et al. Effective migration of antigen-pulsed dendritic cells to lymph nodes in melanoma patients is determined by their maturation state. Cancer Res 2003;63:12-17. 
[25] O’Rourke MG, Johnson M, Lanagan C, See J, Yang J, Bell JR, et al. Durable complete clinical responses in a phase I/II trial using an autologous melanoma cell/dendritic cell vaccine. Cancer Immunol Immunother 2003;52:387-95.

[26] Godelaine D, Carrasco J, Lucas S, Karanikas V, Schuler-Thurner B, Coulie PG, et al. Polyclonal CTL responses observed in melanoma patients vaccinated with dendritic cells pulsed with a MAGE-3.A1 peptide. J Immunol 2003;171:4893-7.

[27] Mailliard RB, Wankowicz-Kalinska A, Cai Q, Wesa A, Hilkens CM, Kapsenberg ML, et al. alpha-type-1 polarized dendritic cells: a novel immunization tool with optimized CTL-inducing activity. Cancer Res 2004;64:5934-7.

[28] ten Brinke A, van Schijndel G, Visser R, de Gruijl TD, Zwaginga JJ, van Ham SM. Monophosphoryl lipid A plus IFNgamma maturation of dendritic cells induces antigenspecific CD8+ cytotoxic $\mathrm{T}$ cells with high cytolytic potential. Cancer Immunol Immunother 2010;59:1185-95.

[29] Felzmann T, Hüttner KG, Breuer SK, Wimmer D, Ressmann G, Wagner D, et al. Semi-mature IL-12 secreting dendritic cells present exogenous antigen to trigger cytolytic immune responses. Cancer Immunol Immunother 2005;54:76980.

[30] Trepiakas R, Pedersen AE, Met O, Hansen MH, Berntsen A, Svane IM. Comparison of alpha-Type-1 polarizing and standard dendritic cell cytokine cocktail for maturation of therapeutic monocyte-derived dendritic cell preparations from cancer patients. Vaccine 2008;26:2824-32.

[31] Jürgens B, Hainz U, Fuchs D, Felzmann T, Heitger A. Interferon-gamma-triggered indoleamine 2,3-dioxygenase competence in human monocyte-derived dendritic cells induces regulatory activity in allogeneic $\mathrm{T}$ cells. Blood 2009;114:3235-43.

[32] Kalinski P. Regulation of immune responses by prostaglandin E2. J Immunol 2012;188:21-8.

[33] De Keijzer S, Meddens MB, Torensma R, Cambi A. The multiple faces of prostaglandin E2 G-protein coupled receptor signaling during the dendritic cell life cycle. Int J Mol Sci 2013;14:6542-55.

[34] Ten Brinke A, Karsten ML, Dieker MC, Zwaginga JJ, van Ham SM. The clinical grade maturation cocktail monophosphoryl lipid A plus IFNgamma generates monocytederived dendritic cells with the capacity to migrate and induce Th1 polarization. Vaccine 2007;25:7145-52.

[35] Zeng L, An S, Goetzl EJ. Independent down-regulation of EP2 and $\mathrm{EP} 3$ subtypes of the prostaglandin $\mathrm{E} 2$ receptors on U937 human monocytic cells. Immunology 1995;86:620-8.

[36] Harizi H, Grosset C, Gualde N. Prostaglandin E2 modulates dendritic cell function via EP2 and EP4 receptor subtypes. J Leukoc Biol 2003;73:756-63.

[37] Hinz B, Brune K, Pahl A. Prostaglandin E(2) upregulates cyclooxygenase-2 expression in lipopolysaccharide-stimulated RAW 264.7 macrophages. Biochem Biophys Res Commun 2000;272:744-8.

[38] D'Amico G, Bianchi G, Bernasconi S, Bersani L, Piemonti L, Sozzani S, et al. Adhesion, transendothelial migration, and reverse transmigration of in vitro cultured dendritic cells. Blood 1998;92:207-14.

[39] Förster R, Schubel A, Breitfeld D, Kremmer E, Renner-Müller I, Wolf E, et al. CCR7 coordinates the primary immune response by establishing functional microenvironments in secondary lymphoid organs. Cell 1999;99:23-33.

[40] Hirao M, Onai N, Hiroishi K, Watkins SC, Matsushima K, Robbins PD, et al. CC chemokine receptor-7 on dendritic cells is induced after interaction with apoptotic tumor cells: critical role in migration from the tumor site to draining lymph nodes. Cancer Res 2000;60:2209-17.

[41] Yen JH, Khayrullina T, Ganea D. PGE2-induced metalloproteinase-9 is essential for dendritic cell migration. Blood 2008;111:260-70.

[42] Krause P, Bruckner M, Uermösi C, Singer E, Groettrup M, Legler DF. Prostaglandin E(2) enhances T-cell proliferation by inducing the costimulatory molecules OX40L, CD70, and 4-1BBL on dendritic cells. Blood 2009;113:2451-60. 